\title{
Effect of Spray Pressure and Height on Interfacial Heat Transfer of H13 Steel during Spray Cooling
}

\author{
Zi-Chao WANG, Hai-Dong ZHAO, ${ }^{*}$ Guo WANG and Yue-Qin LEI \\ National Engineering Research Centre of Near-net Shape Forming for Metallic Materials, South China University of Technol- \\ ogy, Guangzhou, China.
}

(Received on June 5, 2021; accepted on August 20, 2021)

\begin{abstract}
To accurately calculate mold temperature field during spray process of die casting process, the interfacial heat transfer coefficient (IHTC) between the mold and the spray medium is an extremely important thermo-physical parameter. In this paper, a spray experiment was conducted with different spray pressures and heights, in which the temperature history throughout the spray cooling process of $\mathrm{H} 13$ steel plate was recorded. The IHTC under the different spray parameters were calculated by utilizing the nonlinear estimation method. The interface morphology and heat transfer characteristics within the spray cooling process were studied, and the influence of spray pressures and heights on the IHTC was discussed. The results show that the interface can be divided into wet and dry regions, where the former significantly affects the heat transfer behavior on the interface. It is found that high spray pressure has a positive effect on improving peak IHTC whereas it impedes the expansion of wet region and delays the peak of IHTC; reducing spray height leads to the expansion of wet region and the rise of peak IHTC.
\end{abstract}

KEY WORDS: H13 steel; spray cooling; interfacial heat transfer coefficient; inverse method; spray pressure and height.

\section{Introduction}

Die-casting process is widely used in making components for automotive, electronics, communication and other industries, due to its characteristics of high producing efficiency, near net shape and good product surface quality. Accurate simulation of mold temperature field can help to design diecasting process parameters, improve dimensional accuracy of castings, extend mold life, shorten development cycles, and reduce manufacturing costs. During rapid cycles of die-casting producing, spray process is necessary in cooling down and lubricating the mold surface, which has critical influence on the mold temperature field for the next casting.

The interfacial heat transfer coefficient (IHTC) can quantitatively characterize the heat transfer behavior on the interface. Usually, the IHTC of the spray process is set as a constant in the temperature field simulation. However, the studies on spray cooling in the fields of gas quenching and electronic equipment cooling ${ }^{1-8)}$ have shown that the IHTC varies with space and time. ${ }^{9,10}$ Therefore, the IHTC of the mold during the spray process is one of the essential parameters to improve the accuracy in the full cycle temperature simulation of die-casting process. Unfortunately, study on the evolution of the IHTC has not been reported to date.

\footnotetext{
* Corresponding author: E-mail: zhaohaidong@tsinghua.org.cn
}

In present work, to simulate the spray process of diecasting molds, a spray experiment was designed where heat transfer mechanism of H13 steel was investigated. The H13 steel (equivalent to JIS-SKD61 steel) is one of the most used materials for die-casting molds due to its good hightemperature strength, excellent toughness and ductility in all directions, excellent through-hardening properties, and high level of resistance to thermal fatigue and thermal shock. ${ }^{11-13)}$ In the experience, the temperature evolution near the spray cooling interface of the H13 steel plate was recorded, then combined with a self-developed program based on the Beck's nonlinear estimation method, ${ }^{14}$ ) the IHTCs under different spray pressures and heights were solved. Besides, the interface morphology and heat transfer characteristics of the spray cooling process were studied, and the relationship between the spray parameters and the IHTC was discussed.

\section{Experimental}

\subsection{Experimental Material}

The H13 steel was selected as experimental material, which was forged and annealed to obtain fine microstructure, the hardness of the steel after annealing was less than $229 \mathrm{HBW}$. The steel was machined into a $200 \mathrm{~mm} \times 140$ $\mathrm{mm} \times 20 \mathrm{~mm}$ flat plate. Its chemical compositions measured by spectrometer are listed in Table 1, which are sat- 
isfied with ANSI standard. The liquidus temperature of the $\mathrm{H} 13$ steel is $1472^{\circ} \mathrm{C}$, while the working temperature range of the mold is generally $100^{\circ} \mathrm{C}$ to $300^{\circ} \mathrm{C}$ in the die-casting process, which is far below the liquidus temperature.

\subsection{Experimental Set-up}

The schematics of spray cooling device are depicted in Fig. 1, the device consists of an air-water mixed nozzle, gas tank, air compressor, water tank, PLC (programmable logic controller) cabinet, heating equipment, and high-pressure pipe. The experimental plate was placed on an insulated workbench to avoid unnecessary heat loss along downwards direction. The nozzle was fixed on an adjustable aluminum frame. Its spray-cone angle was $30^{\circ}$ and its jet axis was set perpendicular to the workbench. The pipes were connected to the nozzle to supply high-pressure water and air provided by the air compressor, which can be controlled by a pressure regulator within the range of 0.1 to $0.5 \mathrm{MPa}$ ( 1 to 5 bar), and the actual flow rates of water and air were monitored

Table 1. Chemical compositions of the experimental H13 steel (wt\%).

\begin{tabular}{ccccccc}
\hline $\mathrm{C}$ & $\mathrm{Cr}$ & $\mathrm{Mn}$ & $\mathrm{Si}$ & $\mathrm{Mo}$ & $\mathrm{V}$ & $\mathrm{Fe}$ \\
\hline 0.39 & 5.2 & 0.4 & 1.1 & 1.2 & 0.95 & Bal. \\
\hline
\end{tabular}

Liquidus temperature of the $\mathrm{H} 13$ steel is $1472^{\circ} \mathrm{C}$ by flow meters attached to the spraying device. The switch of the nozzle and the spraying time was controlled by the PLC cabinet through the electromagnetic valves. The camera located on top as shown in Fig. 1 was used to record the morphology change of the plate surface during the spray process.

In this experiment, $8 \mathrm{~K}$-type thermocouples with $0.5 \mathrm{~mm}$ diameter, named TC1 to TC8 for convenient description, were linked with a high-accuracy data acquisition system, CoMo MIS 2869B301 (Kistler Co. Lt., Switzerland) to collect temperature data of the plate. The measurement response time is $25 \mathrm{~ms}$ with the frequency $10 \mathrm{HZ} .8$ holes with $1 \mathrm{~mm}$ diameter and $70 \mathrm{~mm}$ depth were drilled from one side of the plate to fix the thermocouples. The layout of temperature measurement points and spray zones are shown in Fig. 2, the temperature data of TC1 toTC6 along the long direction were used to calculate IHTC of six divided spray zones (Z1-Z6), while the data of TC7 and TC8 installed along the thickness direction were used to control the preheating temperature of the plate and to verify the inverse calculation result, respectively.

\subsection{Experimental Procedure}

The experiments were carried out to measure the temperature variation at different points of the H13 plate under different spray pressures and heights. In actual die casting
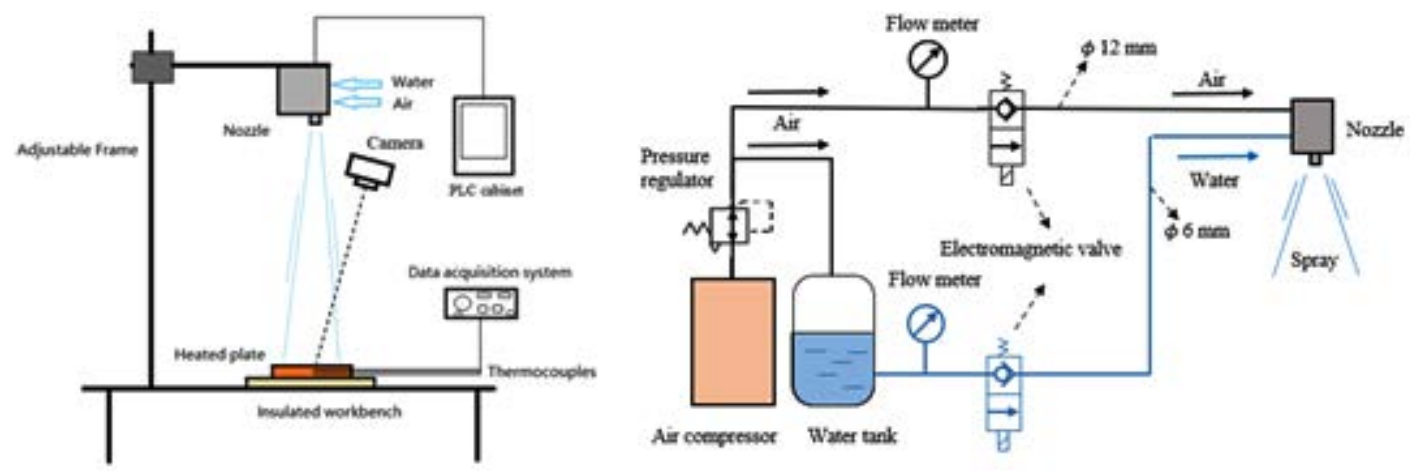

Fig. 1. Schematic diagram of experimental setup. (Online version in color.)
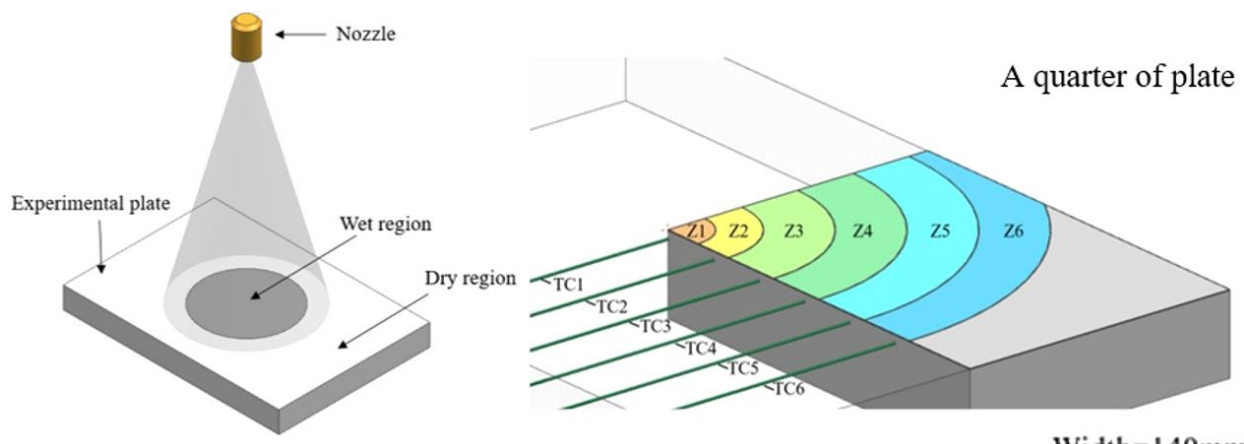

Width $=140 \mathrm{~mm}$

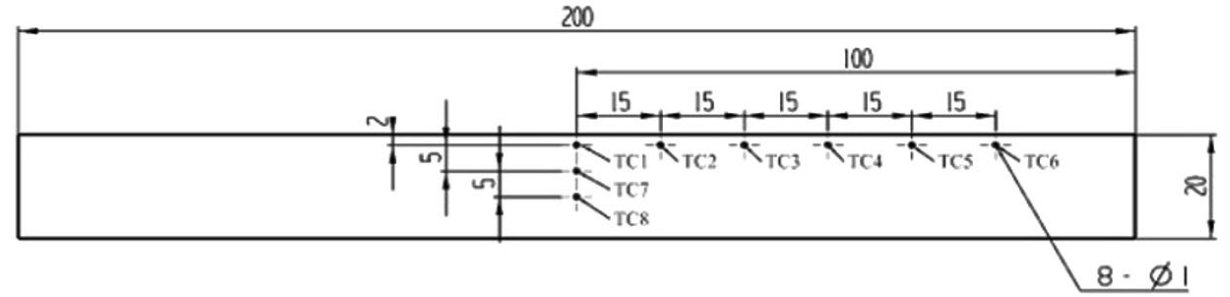

Fig. 2. Layout of temperature measurement points and spray zones. (Online version in color.) 
Table 2. Parameters of the spray cooling experiment.

\begin{tabular}{cccccc}
\hline Mode & $\begin{array}{c}\text { Spray } \\
\text { pressure } \\
(\mathrm{MPa})\end{array}$ & $\begin{array}{c}\text { Spray } \\
\text { height } \\
(\mathrm{mm})\end{array}$ & Mode & $\begin{array}{c}\text { Spray } \\
\text { pressure } \\
(\mathrm{MPa})\end{array}$ & $\begin{array}{c}\text { Spray } \\
\text { height } \\
(\mathrm{mm})\end{array}$ \\
\hline 1 & 0.2 & 200 & 7 & 0.4 & 300 \\
2 & 0.3 & 200 & 8 & 0.5 & 300 \\
3 & 0.4 & 200 & 9 & 0.2 & 400 \\
4 & 0.5 & 200 & 10 & 0.3 & 400 \\
5 & 0.2 & 300 & 11 & 0.4 & 400 \\
6 & 0.3 & 300 & 12 & 0.5 & 400 \\
\hline
\end{tabular}

process, the spray pressure is usually adjusted to 0.3 to 0.4 $\mathrm{MPa}$. Therefore, the spray pressures in this experiment were set to $0.2,0.3,0.4$ and $0.5 \mathrm{MPa}$, and the corresponding flow rates of water measured were $160,180,200,220$, and 240 $\mathrm{ml} / \mathrm{min}$, the flow rates of air were $15,22,29,37 \mathrm{~L} / \mathrm{min}$. The spray heights were set as 200, 300 and $400 \mathrm{~mm}$. The specific spray cooling parameters are summarized in Table 2. Hence, total 12 individual spray experiments were performed. Considering that the temperature of the actual mold is usually between $150^{\circ} \mathrm{C}$ to $250^{\circ} \mathrm{C}$, the initial temperature of the experimental plate was set at $300^{\circ} \mathrm{C}$. Each spraying lasted for $10 \mathrm{~s}$, which is sufficient to the normal spray cooling time required for die-casting. ${ }^{15,16)}$ The temperature evolutions of the plate in $50 \mathrm{~s}$ were recorded, which covered the whole spraying to obtain better computational convergence.

The detailed experiment procedure is as follows:

1) Preset spray cooling parameters;

2) Install thermocouples on the H13 steel plate and fix it on the workbench (the center of the plate is directly below the nozzle);

3) Heat the plate to $300^{\circ} \mathrm{C}$ with a contact heating device and keep for a while to ensure even distribution of the plate temperature;

4) Turn on the spray device and start to record the temperature evolution (the spraying lasts for $10 \mathrm{~s}$ );

5) Turn off the spray and save the temperature results.

\section{Inverse Calculation of IHTC}

\subsection{Mathematical Model}

The inverse algorithm adopted in this work is based on the Beck's nonlinear inverse method..$^{14,17,18)}$ In order to acquire accurate IHTC, the actual plate temperature and heat transfer boundary condition should be confirmed, and then the optimal IHTC values can be obtained by minimizing the difference between the calculated and measured temperatures.

The temperatures recorded by $N$ thermocouples are involved in the calculation. The entire spray process can be divided into several pieces of time interval, and each one can be sub-divided into $r$ sub-pieces of future times. The IHTCs are assumed to be same in each time interval, for the $L^{\text {th }}$ interval:

$$
h_{L}=h_{L+i}(i=1,2, \ldots, r-1)
$$

The objective function can be defined by the following equation in the $L^{\text {th: }}$

$$
F\left(h_{L}\right)=\sum_{i=1}^{N} \sum_{j=0}^{r-1}\left(T_{i, L+j}^{m}-T_{i, L+j}^{c}\right)^{2}
$$

The necessary condition for the objective function to obtain the minimum value is

$$
\begin{aligned}
& \frac{\partial F\left(h_{L}\right)}{\partial h_{L}}=0 \\
& \text { or } \sum_{i=1}^{N} \sum_{j=0}^{r-1}\left(T_{i, L+j}^{m}-T_{i, L+j}^{c}\left(h_{L}\right)\right) \frac{\partial T_{i, L+j}^{c}}{\partial h_{L}}=0
\end{aligned}
$$

The calculated temperature, $T_{i, L+j}^{c}\left(h_{L}\right)$, can be differentiated based on Taylor expansion, written as

$$
T_{i, L+j}^{c}\left(h_{L}\right)=T_{i, L+j}^{c^{*}}\left(h_{L}^{*}\right)+\frac{\partial T_{i, L+j}^{c}}{\partial h_{L}} \Delta h_{L}
$$

where

$$
\Delta h_{L}=h_{L}-h_{L}{ }^{*}
$$

The sensitivity coefficient ${ }^{19-21)}$ of the calculated temperature $\varphi_{i, L+j}$ can be solved by

$$
\varphi_{i, L+j}=\frac{\partial T_{i, L+j}^{c}}{\partial h_{L}}=\frac{T_{i, L+j}^{c}\left[(1+\varepsilon) h_{L}\right]-T_{i, L+j}^{c}\left(h_{L}\right)}{\varepsilon h_{L}} \ldots
$$

Where, $\varepsilon$ was set as 0.001 in this study. Introducing Eqs. (5)-(7) to Eq. (3) yields

$$
\Delta h_{L}=\frac{\sum_{i=1}^{N} \sum_{j=0}^{r-1}\left(T_{i, L+j}^{m}-T_{i, L+j}^{c}\right) \times \varphi_{i, L+j}}{\sum_{i=1}^{N} \sum_{j=0}^{r-1}\left(\varphi_{i, L+j}\right)^{2}}
$$

The current IHTC $h_{L}$ is calculated by adding previous IHTC $h_{L}{ }^{*}$ and increment $\Delta h_{L}$. In each time interval, the IHTC is modified continuously until $\left|\frac{\Delta h_{L}}{h_{L}}\right| \leq E$.

\subsection{Calculation Procedure}

The IHTC of spray process was solved by a self-developed program based on the above model, which is implemented through the User Development Function (UDF) of software ANSYS Mechanical (ANSYS Co. Lt., the United States). The program can repeatedly call the ANSYS to solve the heat transfer and temperature field, and the TimeIHTC curve can be obtained by introducing the simulation and experiment results into Eq. (8). The flowchart is shown in Fig. 3 and the solution procedure is as follows.

1) Read the temperature data with time at the measurement points during the experiment;

2) Import the finite element (FE) model and set initial $h_{0}$ and other boundary conditions;

3) Call ANSYS to calculate the temperature field of the plate;

4) Calculate the sensitivity coefficient $\varphi_{i}$ and the IHTC increment $\Delta h$;

5) Continuously modify $h$ until the convergence condition; 6) Output $h$ until the end of calculation.

The thermo-physical properties of $\mathrm{H} 13$ plate were set as variables with temperature, as shown in Table $3 .^{22)}$ The preheating temperature of the plate was $300^{\circ} \mathrm{C}$ and the ambient temperature was set to $25^{\circ} \mathrm{C}$. Because there was a difference of $2-3^{\circ} \mathrm{C}$ between the plate center and the edge after preheating, in order to improve the simulation accuracy, the measured plate temperatures from the thermocouples 
were set as the initial temperatures in this calculation. The recorded temperature changes throughout the whole experiment were adopted in the IHTC calculation, so the total calculation time was $50 \mathrm{~s}$. In order to ensure the accuracy

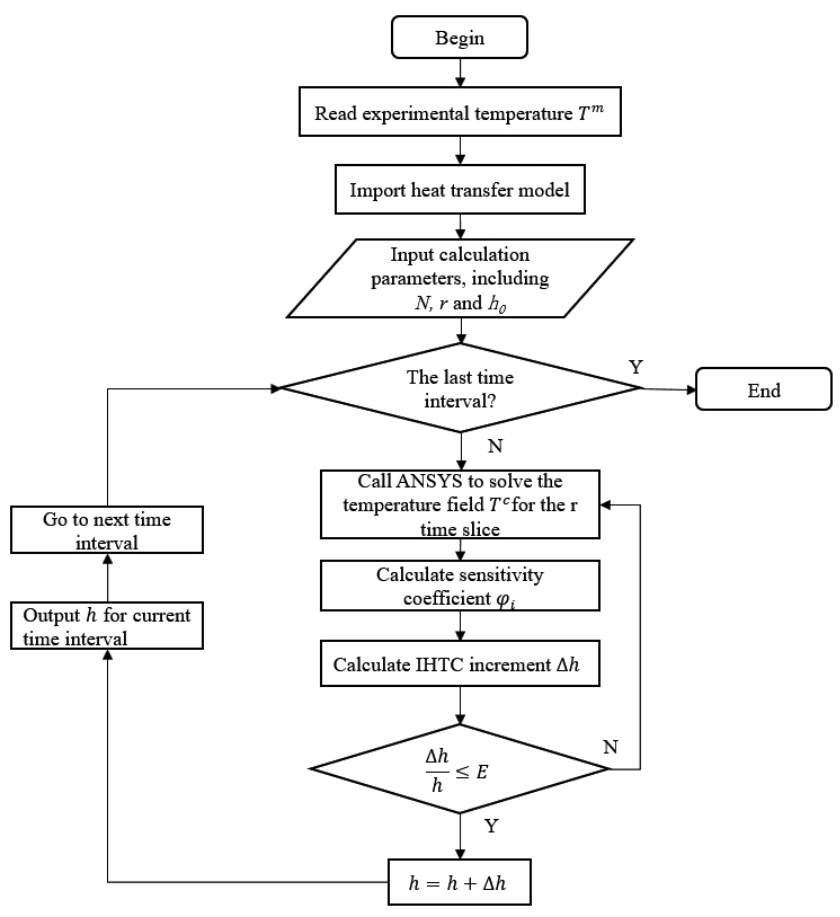

Fig. 3. Flowchart of inverse calculation based on ANSYS.

Table 3. Thermo-physical properties of $\mathrm{H} 13$ steel.

\begin{tabular}{cccc}
\hline Temperature $\left({ }^{\circ} \mathrm{C}\right)$ & 25 & 300 & 500 \\
\hline Thermal conductivity $\left(\mathrm{W} / \mathrm{m}^{\circ}{ }^{\circ} \mathrm{C}\right)$ & 25 & 27.4 & 28.9 \\
Specific heat $\left(\mathrm{J} /\left(\mathrm{g} \cdot{ }^{\circ} \mathrm{C}\right)\right)$ & 460 & 512 & 548 \\
Density $\left(\mathrm{kg} / \mathrm{m}^{3}\right)$ & 7810 & 7640 & 7627 \\
\hline
\end{tabular}

Table 4. Distribution of each spray zone.

\begin{tabular}{ccccccc}
\hline Thermocouple & TC1 & TC2 & TC3 & TC4 & TC5 & TC6 \\
\hline Coordinate X (mm) & 0 & 15 & 30 & 45 & 60 & 75 \\
Spray zone & Z1 & Z2 & Z3 & Z4 & Z5 & Z6 \\
Zone Radius (mm) & {$[0,10)$} & {$[10,20)$} & {$[20,35)$} & {$[35,50)$} & {$[50,65)$} & {$[65,80)$} \\
\hline
\end{tabular}

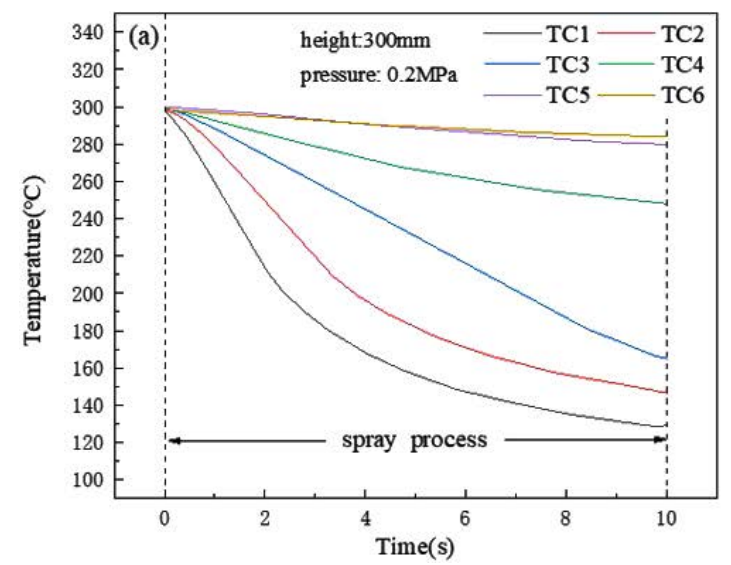

of the calculation on the premise of convergence, the time interval was set to $1 \mathrm{~s}$ and the future time interval was set to $0.05 \mathrm{~s}$. Therefore, $50 \mathrm{IHTC}$ for each point during the spraying were acquired, and 20 temperatures were involved in calculating each IHTC within a time interval. But only the IHTCs in the $10 \mathrm{~s}$ after the spraying started would be discussed in this paper since the IHTCs after the time showed very few changes.

According to the location of the thermocouples, the spray interface was divided into 6 spray zones by concentric circles, as shown in Fig. 2. And the positional relationship between the spray zones and the corresponding thermocouples can be seen in Table 4. A comprehensive heat transfer coefficient $h$ was introduced to describe the complex heat transfer behavior on each zone. It was assuming that the IHTC on each spray zone was same in a time interval and only changes with time as well as was independent of each other. The bottom of the model was set to be an adiabatic interface, and other interfaces were set to air convection interface, where the convection coefficient in the calculation was $20 \mathrm{~W} /\left(\mathrm{m}^{2} \cdot{ }^{\circ} \mathrm{C}\right) .{ }^{23)}$

\section{Results}

\subsection{Temperature Evolution}

The temperatures at TC1-TC6 were recorded during the spray cooling of $\mathrm{H} 13$ steel plate, and the time-temperature curves under the pressures of 0.2 and $0.4 \mathrm{MPa}$ are given in Fig. 4. It can be seen that since the spraying started, all temperatures began to drop. The temperature at TC1 and TC2 near the center went down faster and were significantly lower than the other points, indicating that the spray center was cooled down first. It is interesting that the minimum temperature of TC3 at the pressure of $0.4 \mathrm{MPa}$ was significantly higher than that at the $0.2 \mathrm{MPa}$ pressure. This will be discussed in section 4.1.

\subsection{IHTC of Inverse Calculation}

\subsubsection{Verification of Inverse Calculation}

Since the measured temperature evolution of TC7 was not involved in the inverse calculation, it could be used to validate the inverse calculation, namely comparing with the simulated temperature there by input the calculated IHTCs as the interface condition. The result of comparison under

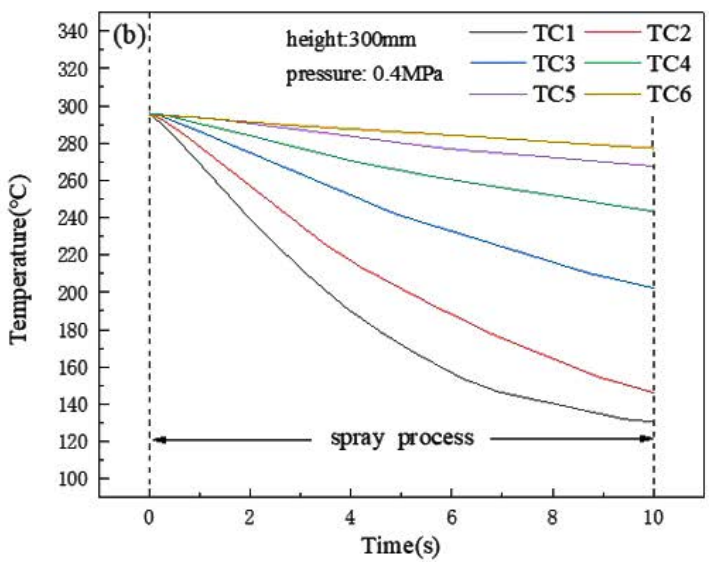

Fig. 4. Measured temperature of the $\mathrm{H} 13$ plate (a) $\mathrm{h}=300 \mathrm{~mm}, \mathrm{p}=0.2 \mathrm{MPa}$ (b) $\mathrm{h}=300 \mathrm{~mm}, \mathrm{p}=0.4 \mathrm{MPa}$. (Online version in color.) 
the pressure of $0.5 \mathrm{MPa}$ and the height of $300 \mathrm{~mm}$ is shown in Fig. 5, showing well agreement. The maximum relative deviation in the figure is only about $1.6 \%$, which is quite lower than those in literatures. ${ }^{1,24,25)}$ This confirms the validity of the inverse calculation.

\subsubsection{IHTC Results}

The Time-IHTC curves under the different spray parameters are given in Fig. 6. Since the spraying started, the IHTCs, especially those near the center of the plate, rose significantly. Afterwards, the IHTCs in the center went down after its peak, while those away from the center continued to rise. Figures $6(\mathrm{a})-6(\mathrm{~d})$ show the results with the different spray pressures, as the spray pressure increased, the time for the IHTC on center to its peak was delayed but the peak value only showed little change. In case of the

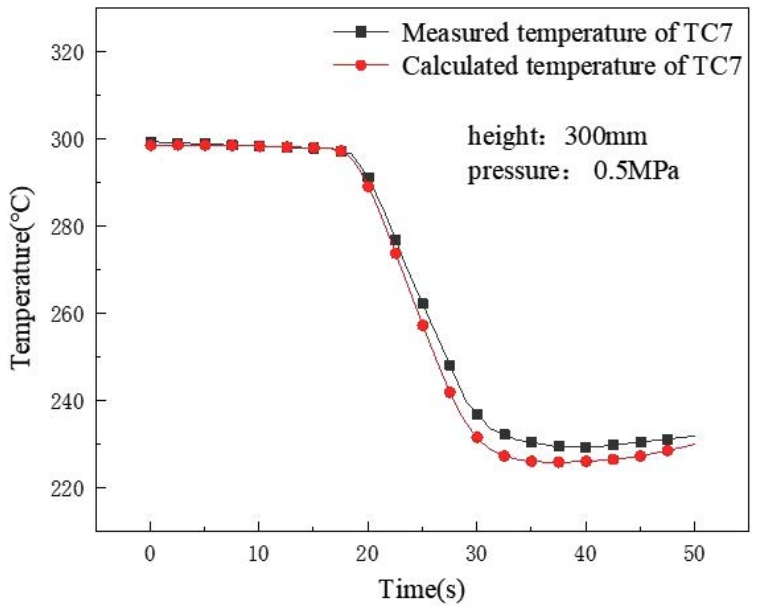

Fig. 5. Comparison between measured and calculated temperature curves (TC7). (Online version in color.)
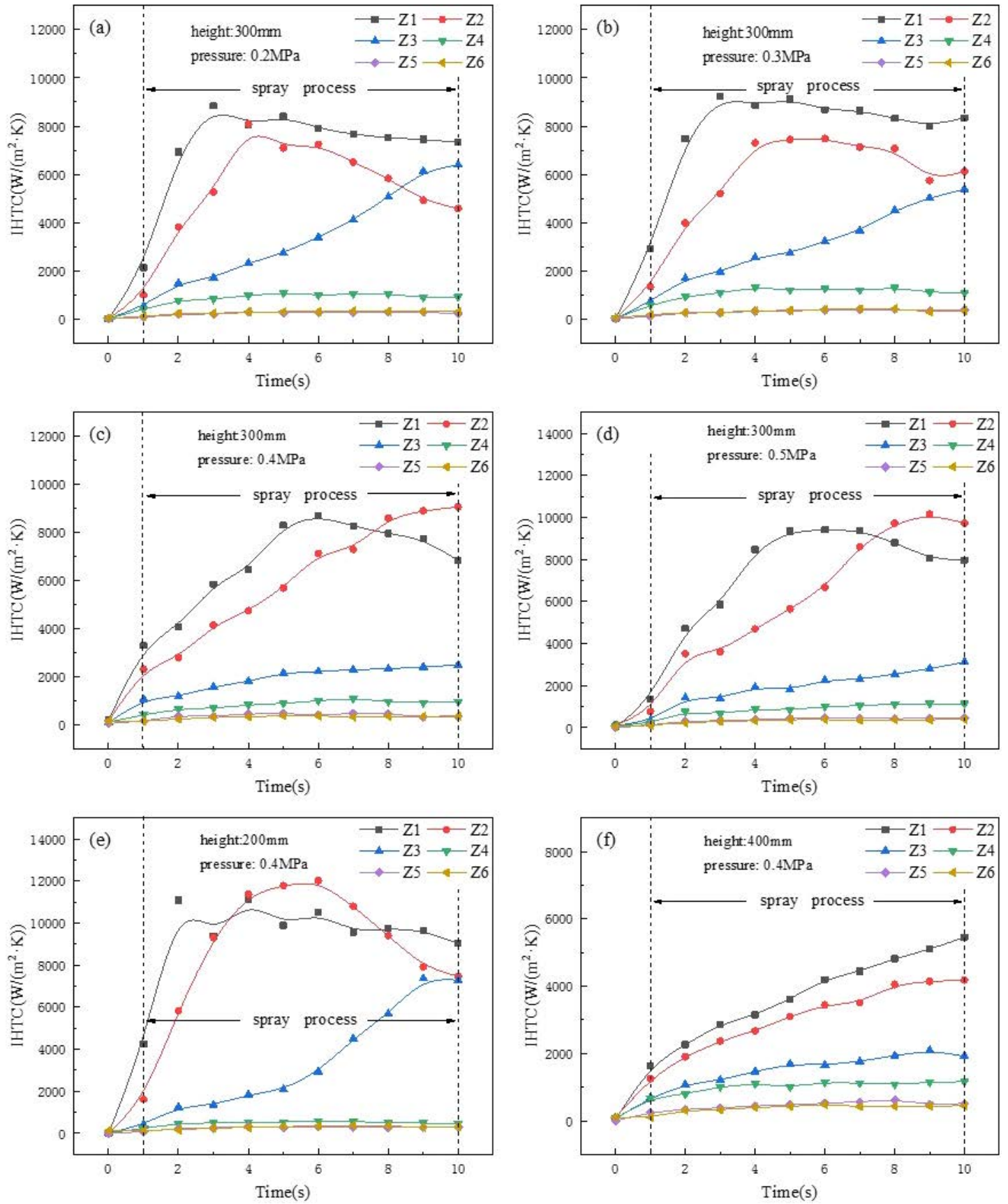

Fig. 6. Time-IHTC curves under different spray parameters (p/h) (a) $0.2 \mathrm{MPa} / 300 \mathrm{~mm}$ (b) $0.3 \mathrm{MPa} / 300 \mathrm{~mm}$ (c) 0.4 $\mathrm{MPa} / 300 \mathrm{~mm}$ (d) $0.5 \mathrm{MPa} / 300 \mathrm{~mm}$ (e) $0.4 \mathrm{MPa} / 200 \mathrm{~mm}$ (f) $0.4 \mathrm{MPa} / 400 \mathrm{~mm}$. (Online version in color.) 
higher spray pressure, the IHTC on Z2 exceeds that on Z1, as shown in Figs. 6(c) and 6(d). This phenomenon is closely relative to the wet region evolution, which will be discussed later in section 4.3. Figures 6(c), 6(e), and 6(f) show the results with the different spray heights, as the spray height increased, the peak value of IHTC in the center dropped significantly and the appearing time of the peak was delayed.

\subsection{Spray Morphology}

Figure 7 shows the spray interface characteristics under the pressure of $0.4 \mathrm{MPa}$ and height of $300 \mathrm{~mm}$. When the spraying began, the droplets gradually deposited in the interface center, forming a near-circular radial region, which was covered and wetted by a water film. This region is socalled the wet region and the residual region is dry region. Clearly the region expanded with the spraying time. The heat transfer between the plate and the spray medium was mainly determined by the vaporization and convection with water, vapor and air. Because of the big difference between the spray medium and plate temperatures in the beginning, the droplets evaporated rapidly as contacting the high-temperature plate, in which a lot of energy was removed from the plate. Therefore, the center of the interface was cooled down first (Fig. 4). The temperature dropped in the center decreased the evaporation of the arriving droplets, and then the wet region began to form in the center (Fig. 7(a)). This further decreased the temperature of regions around the center, promoting the deposition of more droplets and the expansion of the region as shown in Figs. 7(b) and 7(c).

Since the heat flux evolution through the interface is helpful to better understanding of the heat transfer mechanism within the spray cooling process, an additional spray cooling experiment was conducted to obtain the boiling curve of the process. In this experiment, the spray time was extended to $100 \mathrm{~s}$; the initial temperature of the plate was set to $300^{\circ} \mathrm{C}$; the spray pressure and height were set to $0.4 \mathrm{MPa}$ and 300 $\mathrm{mm}$, respectively. After solving the IHTC of the interface center with the developed program, the heat flux could be calculated by

$$
q=h \times \Delta T
$$

Figure 8 depicts the variation of heat flux from the surface to the spray with wall superheat (wall temperature minus liquid saturation temperature), which agrees with the typical boiling curve below the Leidenfrost point. ${ }^{26)}$ According to the literature, the cooling process can be mainly divided into the following three stages as indicated in Fig. 8: (I) Transitional boiling stage (stage), (II) Nucleating boiling stage, and (III) Single-phase stage. These stages have significant influences on cooling effectiveness.
According to the evolution of wet region on the spray interface in Fig. 7 and the corresponding Time-IHTC curves in Fig. 6(c), in the early stage of the spray the interface was at transitional boiling stage. In the stage, due to high superheat the droplets vaporized when contacting with the hot plate. Then only vapor films could form although the IHTC of the interface center rose continuously (Fig. 6(c)). With the superheat decrease, the vaporization was decreased and the center began to be wet (Fig. 7(a)). After that, more and more water deposited on the center and the water film formed. Then the wet region completely covered Z1 at 6 s. The strong convection of water film promoted the heat transfer so that the local IHTC reached its peak (Fig. 7(b)). The period since Fig. 7(a) was belong to nucleation boiling stage, and the cooling process did not have single phase stage because the center temperature was higher than the boiling temperature of the spray water. With the proceeding of the spray, the wet region grew and completely covered $\mathrm{Z} 2$ at $10 \mathrm{~s}$, leading the cooling there into nucleation boiling stage and peak IHTC (Fig. 7(c)). At the time, the superheat in the center further decreased. This is the reason that the IHTC on Z2 exceeds that on Z1 in Fig. 6(c) with the spray proceeding.

\section{Discussion}

\subsection{Effect of Spray Pressure on Wet Region}

According to the Figs. 6(c) and 7(c), the IHTC on Z2 near the edge of wet region had a higher peak value compared to that on Z1. Because the droplet fell away from the center had a high horizontal component of velocity, the convection at the edge of the wet region was improved, increasing the

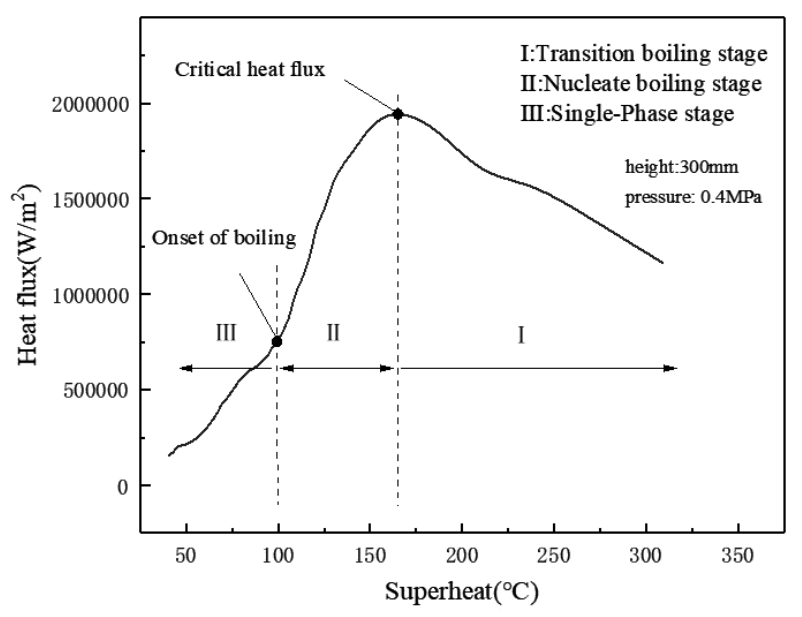

Fig. 8. Boiling curve of $\mathrm{H} 13$ plate in spray cooling process (spray time $100 \mathrm{~s}, \mathrm{p}=0.4 \mathrm{MPa}, \mathrm{h}=300 \mathrm{~mm})$.

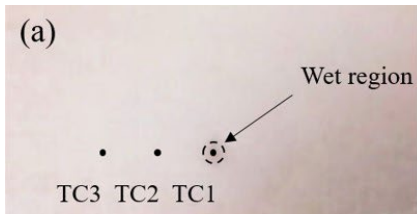

(b)

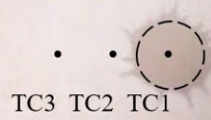

(c)

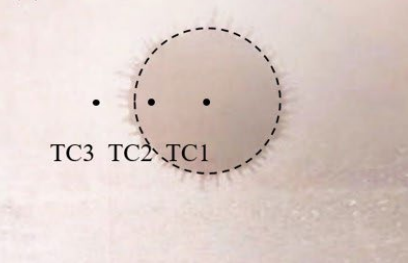

Fig. 7. Characteristics of spray interface at different time (a) $3 \mathrm{~s} \mathrm{(b)} 6 \mathrm{~s}$ (c) $10 \mathrm{~s}$ (p=0.4 MPa, $\mathrm{h}=300 \mathrm{~mm}$ ). (Online version in color.) 
local IHTC. Therefore, the IHTC distribution at a time can indicate the wet region edge or size. Figures 6(a)-6(d) show that under the pressures of 0.2 and $0.3 \mathrm{MPa}$, the IHTCs on Z3 were higher than those under higher pressure, and the IHTCs on Z3 exceeded that on Z2 at $9 \mathrm{~s}$ under the pressure of $0.2 \mathrm{MPa}$. While under the pressures of 0.4 and $0.5 \mathrm{MPa}$, the IHTC on Z2 exceeded those on Z1 at $8 \mathrm{~s}$, whereas the IHTCs on Z3 went far below that on Z2. It is implied that the wet region decreased with the increase of spray pressure. This caused that the minimum temperature of TC 3 at the 0.4 MPa pressure was significantly higher than that at the 0.2 MPa pressure in Fig. 4.

Under low spray pressure, due to the poor atomization effect on the spray medium, the droplets in the spray could concentrate more easily on the central part, and the size of the droplets were increased. As a result, the temperature of the part decreased more rapidly, as can be seen in Fig. 4 showing a higher cooling rate in the center under the low spray pressure. The higher cooling rate led to the lower superheat on the interface. This decreased the vaporization of the droplets and thereby the droplets were easier to deposit, which helped to form a water film. The formed film could flow outwards, driving the wet region to Z3. As a result, the IHTC there increased as shown in Figs. 6(a) and 6(b). On the contrary, when using high spray pressure, the strong atomization effect decreased the droplets size. It was more difficult for them to deposit on the interface, impeding the formation and expansion of wet region. In result, the final wet region was smaller compared to that in the low spray pressure, which can be also implied by the lower IHTC on Z3 in Figs. 6(c) and 6(d).

\subsection{Effect of Spray Pressure on IHTC Peak Value}

The Time-IHTC curves of Z1 and Z2 under the different pressures $(0.2-0.5 \mathrm{MPa})$ and spray height of $300 \mathrm{~mm}$ are plotted in Fig. 9. As the pressure increased, as shown in Fig. 9(a), the IHTC peak values on Z1 are $8470,9159,8712$, and $9634 \mathrm{~W} /\left(\mathrm{m}^{2} \cdot{ }^{\circ} \mathrm{C}\right)$, and the times to reach the peaks are $3,3,6$, and $6 \mathrm{~s}$, respectively. The values of $\mathrm{Z} 2$ are 7599 , 7460,8930 , and $10028 \mathrm{~W} /\left(\mathrm{m}^{2}{ }^{\circ} \mathrm{C}\right)$ and the times to reach the peaks are 4, 6, 9, and $9 \mathrm{~s}$, as can be seen in Fig. 9(b). Therefore, as the spray pressure increased the peak value of IHTC in the interface center increased and the time to the peak was delayed.

On the one hand, the high spray pressure could increase the velocity of airflow and droplets passing through the nozzle. This surely enhanced the water convection on the wet region and the air convection in the drying region. On the other hand, the high pressure could enhance the atomization effect, decreasing the droplet size and increasing the droplet dispersion. In the early stage of spraying, the surface temperature of the plate was relatively high and local vapor film could form due to the rapid vaporization of the decreased droplet, hindering direct heat flux between the water and the plate. As a result, when using the higher spray pressure, the IHTC in the early spray period was lower compared to that at the lower pressure, and the time of IHTC peak was delayed, as shown in Fig. 9. Although the formation of wet region in the center was delayed, however, the higher pressure can cause intense water convection after the wet region formation. Therefore, for Z1 (Fig. 9(a)) the IHTC peak values at the higher pressures $(0.4$ and $0.5 \mathrm{MPa})$ were a little higher compared to those at the lower pressures $(0.2$ and $0.3 \mathrm{MPa}$ ); for Z2 (Fig. 9(b)) the values at the higher pressures were much more than those at the lower pressures. The above results imply that in actual die casting producing, when adopting high spray pressures, the spray time should be sufficient for the required cooling intensity.

\subsection{Effect of Spray Height on IHTC}

By comparing the Time-IHTC curves under the heights of $200 \mathrm{~mm}, 300 \mathrm{~mm}$, and $400 \mathrm{~mm}$ in Figs. 7(e), 7(c), and 7(f), it can be found that as the spray height increased, the wet region decreased and even disappeared and the peak IHTC decreased as well. Under the spray height of $200 \mathrm{~mm}$, the IHTC on Z2 reached its peak at $6 \mathrm{~s}$. Then it gradually decreased while the IHTC on Z3 increased significantly, indicating that the wet region reached to $\mathrm{Z} 3$ at the end of the spray. Under the spray height of $300 \mathrm{~mm}$ the wet region only covered Z2 at the end of the spraying. When the height increased to $400 \mathrm{~mm}$, the wet region did not form on the surface, and the heat flux was caused by air convection and vaporization. In the case, the IHTC peak of each spray zone appeared at the stop of the spray but was very low.

As the spray height increased, the dispersion range of droplets was enlarged and fewer droplets fell on the central
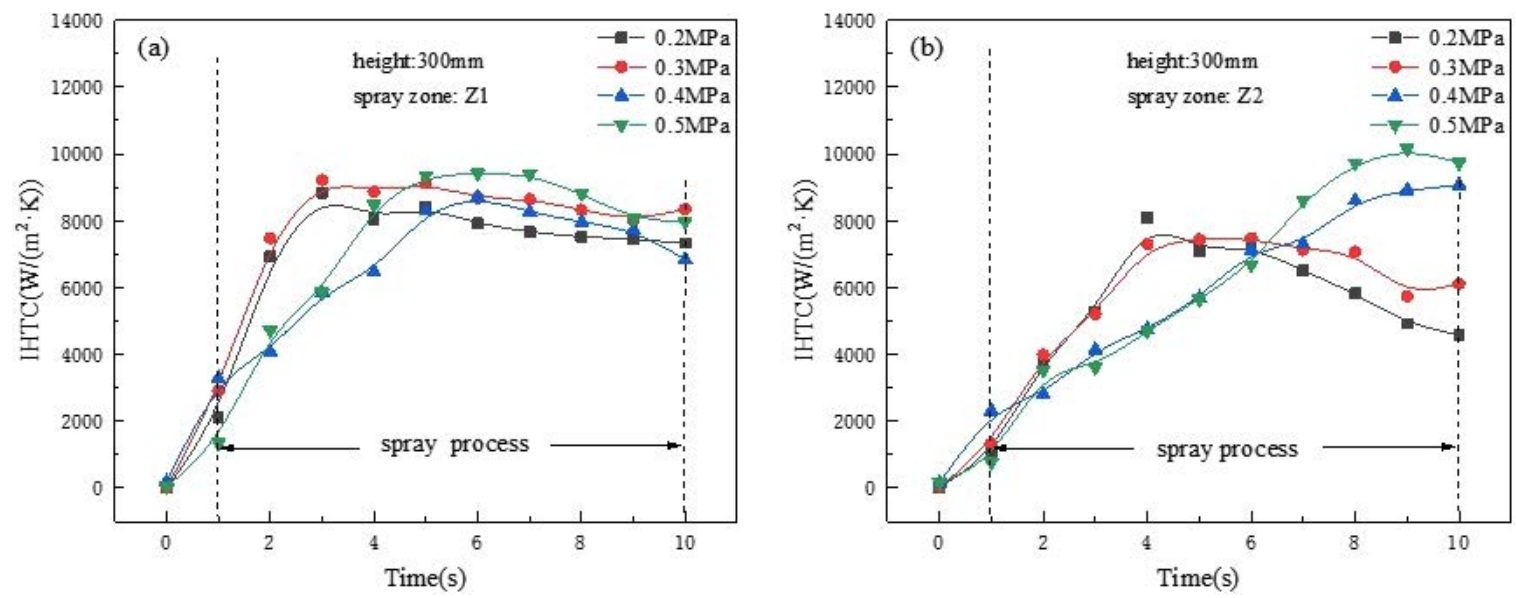

Fig. 9. Time-IHTC curve under different spray pressure at $300 \mathrm{~mm}$ height (a) Z1 (b) Z2 in spray cooling process (spray time $100 \mathrm{~s}, \mathrm{p}=0.4 \mathrm{MPa}, \mathrm{h}=300 \mathrm{~mm}$ ). (Online version in color.) 
part. Therefore, the cooling of the part was weakened and the water film was difficult to form. This was surely unfavored for the expansion of wet region. Thus, the wet region decreased. When the height was high enough, no wet region could form. Furthermore, in the case of low spray height, the velocity of droplets in the direction perpendicular to the surface was high, and hence the flow velocity of the water film increased resulting in intense convection. Therefore, as can be observed from Figs. 6(e), 6(c), and 6(f) the peak values of IHTC increased with the decrease of spray heights.

\section{Conclusion}

In this study, the temperature variation of the H13 steel plate under the different spray pressures and heights was measured. The IHTC of the spray process was solved based on the Beck's nonlinear estimation method. The spray morphology and its relation to the IHTC were investigated, and the effect of the spray pressure and height on the wet region and the IHTC was discussed. It has been shown:

(1) When using the low pressure, the interface center cooled down rapidly. It was easy to form a water film there. Hence the central IHTC reached to its peak early. The early formation of the film also caused the large wet region. On the contrary, the high spray pressure decreased the droplet size, promoting the vaporization on the interface. The formation and expansion of the wet region were impeded. The central IHTC went up slowly. But it had higher peak value compared to that in the low pressure due to the more intense convection in the water film.

(2) For the low spray height, the superheat on the center decreased more rapidly and the water film formed early. Therefore, the IHTC on the center increased dramatically and reached a high peak value. The final wet region was large. With the height increase, the peak value of IHTC decreased and the time to the peak was delayed. When the height increased to a certain level, wet region would not form and the peak value of IHTC decreased significantly.

\section{Acknowledgments}

The research was supported by Key-Area Research and Development Program of Guangdong Province (2020B010186002) and Project of Key Technology Program of Foshan (1920001001040).

\section{Nomenclature}

E: Judgement factor

$h$ : Interfacial heat transfer coefficient (IHTC), (W/ $\mathrm{m}^{2} \cdot{ }^{\circ} \mathrm{C}$ )

h: Spray height, $\mathrm{mm}$

$h_{L}$ : IHTC in the current time interval, $\left(\mathrm{W} / \mathrm{m}^{2} \cdot{ }^{\circ} \mathrm{C}\right)$

$h_{L}{ }^{*}$ : IHTC in last calculation, $\left(\mathrm{W} / \mathrm{m}^{2} \cdot{ }^{\circ} \mathrm{C}\right)$

$h_{0}$ : Assumed initial IHTC, $\left(\mathrm{W} / \mathrm{m}^{2} \cdot{ }^{\circ} \mathrm{C}\right)$

$\Delta h$ : Increment of IHTC, $\left(\mathrm{W} / \mathrm{m}^{2} \cdot{ }^{\circ} \mathrm{C}\right)$

$N$ : Number of thermocouples

p: Spray pressure, MPa

$r$ : Number of future times $r_{w}$ : Radius of wet region, $\mathrm{mm}$

$\mathrm{R}$ : Radius, mm

t: Time, $\mathrm{s}$

T: Temperature, ${ }^{\circ} \mathrm{C}$

$T^{C}$ : Calculated value of temperature field

$T^{m}$ : Measured value of temperature field

$\Delta T$ : Temperature difference at the plate/spray interface, so-called superheat, ${ }^{\circ} \mathrm{C}$

$\varepsilon$ : A tiny quantity

$\varphi$ : Sensitivity coefficient

\section{REFERENCES}

1) L. Ying, T. H. Gao, M. H. Dai, Y. H. Yang and P. Hu: Appl. Therm. Eng., 121 (2017), 48. https://doi.org/10.1016/j. applthermaleng.2017.04.029

2) L. J. Jiang, S. L. Jiang, W. L. Cheng, Y. L. Nian and R. Zhao: Appl. Therm. Eng., 154 (2019), 150. https://doi.org/10.1016/j. applthermaleng.2019.03.078

3) D. Schweigert, B. Damson, H. Lüders, M. Börnhorst and O. Deutschmann: Int. J. Heat Fluid Flow, 78 (2019), 108432. https:// doi.org/10.1016/j.ijheatfluidflow.2019.108432

4) A. Cebo-Rudnicka and Z. Malinowski: Int. J. Therm. Sci., 145 (2019), 106038. https://doi.org/10.1016/j.ijthermalsci.2019.106038

5) G. T. Liang and I. Mudawar: Int. J. Heat Mass Transf., 115 (2017), 1174. https://doi.org/10.1016/j.ijheatmasstransfer.2017.06.029

6) G. T. Liang and I. Mudawar: Int. J. Heat Mass Transf., 115 (2017), 1206. https://doi.org/10.1016/j.ijheatmasstransfer.2017.06.022

7) D. Li, B. Chen, W. J. Wu, G. X. Wang and Y. L. He: Appl. Therm. Eng., 73 (2014), 1489. https://doi.org/10.1016/j. applthermaleng.2014.03.034

8) M. H. Sadafi, S. González Ruiz, M. R. Vetrano, I. Jahn, J. van Beeck, J. M. Buchlin and K. Hooman: Energy Convers. Manag., 108 (2016), 336. https://doi.org/10.1016/j.enconman.2015.11.025

9) B. Horacek, K. T. Kiger and J. Kim: Int. J. Heat Mass Transf., 48 (2005), 1425. https://doi.org/10.1016/j.ijheatmasstransfer.2004.10.026

10) J. Kim: Int. J. Heat Fluid Flow, 28 (2007), 753. https://doi. org/10.1016/j.ijheatfluidflow.2006.09.003

11) L. Wang, J. Li, B. Ning and Y. Y. Li: Mater. Trans., 55 (2014), 1104. https://doi.org/10.2320/matertrans.M2014086

12) S. Chang, T. Tang and K. Huang: ISIJ Int., 50 (2010), 569. https:// doi.org/10.2355/isijinternational.50.569

13) M. Koneshlou, K. M. Asl and F. Khomamizadeh: Cryogenics, 51 (2011), 55. https://doi.org/10.1016/j.cryogenics.2010.11.001

14) J. Beck, B. Blackwell and C. Clair: Inverse Heat Conduction, John Wiley \& Sons, Inc., New York, (1985), 1.

15) A. Long, D. Thornhill, C. Armstrong and D. Watson: Appl. Therm. Eng., 44 (2012), 100. https://doi.org/10.1016/j.applthermaleng.2012.03.045

16) G. Campatelli and A. Scippa: Simul. Model. Pract. Theory, 22 (2012), 109. https://doi.org/10.1016/j.simpat.2011.11.003

17) J. Beck: Int. J. Heat Mass Transf., 13 (1970), 703. https://doi. org/10.1016/0017-9310(70)90044-X

18) J. Beck, B. Blackwell and A. Haji-Sheikh: Int. J. Heat Mass Transf., 39 (1996), 3649. https://doi.org/10.1016/0017-9310(96)00034-8

19) I. L. Ferreira, J. E. Spinelli, J. C. Pires and A. Garcia: Mater. Sci. Eng. A, 408 (2005), 317. https://doi.org/10.1016/j.msea.2005.08.145

20) T. S. Prasanna Kumar and H. C. Kamath: Metall. Mater. Trans. B, 35 (2004), 575. https://doi.org/10.1007/s11663-004-0056-y

21) J. E. Spinelli, N. Cheung, P. R. Goulart, J. M. V. Quaresma and A. Garcia: Int. J. Therm. Sci., 51 (2012), 145. https://doi.org/10.1016/j. ijthermalsci.2011.08.014

22) MatWeb, LLC: Bohler-Uddeholm UDDEHOLM ORVAR SUPERIOR (Premium AISI H13) Hot Work Tool Steel, MatWeb, http://www. matweb.com/search/DataSheet.aspx?MatGUID = 84e679b95ef74471 865e8543dadbfeb5\&ckck=1, (accessed 2021-03-20).

23) W. Zhu, Z. Q. Han and B. C. Liu: Acta Metall. Sin., 45 (2009), 363 (in Chinese). https://doi.org/10.3321/j.issn:0412-1961.2009.03.018

24) J. H. Lin, H. D. Zhao and J. M. Huang: Trans. Nonferrous Met. Soc. China, 29 (2019), 43. https://doi.org/10.1016/S10036326(18)64913-1

25) A. Hamasaiid, M. S. Dargusch, C. J. Davidson, S. Tovar, T. Loulou, F. Rezaï-Aria and G. Dour: Metall. Mater. Trans. A, 38 (2007), 1303. https://doi.org/10.1007/s11661-007-9145-2

26) N. Mascarenhas and I. Mudawar: Int. J. Heat Mass Transf., 53 (2010), 5871. https://doi.org/10.1016/j.ijheatmasstransfer.2010.06.055 